\title{
Effect of glycomacropeptide fractions on cholecystokinin and food intake
}

\author{
Jennifer B. Keogh ${ }^{1 *}$, Brad W. Woonton ${ }^{2}$, Cheryl M. Taylor ${ }^{2}$, Filip Janakievski ${ }^{2}$, Kirthi Desilva ${ }^{2}$ \\ and Peter M. Clifton ${ }^{1}$ \\ ${ }^{1}$ CSIRO Preventative Health Flagship, Food and Nutritional Sciences, Kintore Avenue, Adelaide SA 5000, Australia \\ ${ }^{2}$ CSIRO Food Futures Flagship, Food and Nutritional Sciences, 671 Sneydes Road, Werribee, Vic 3030, Australia \\ (Received 3 September 2009 - Revised 13 January 2010 - Accepted 15 January 2010 - First published online 8 March 2010)
}

Glycomacropeptide (GMP) is the hydrophilic 64-amino acid C-terminal glycopeptide released into cheese whey when $\mathrm{\kappa}$-casein is cleaved by chymosin. GMP exists as a mixture of different glycoforms due to the carbohydrates sialic acid ( $N$-acetylneuraminic acid, Neu $N A c)$, galactose (Gal), galactosamine and glucosamine attached by $O$-glycosidic linkages. GMP reportedly stimulates the release of cholecystokinin (CCK), which may promote satiety. The objectives of the present study were to manufacture three glycoforms of GMP, minimally glycosylated GMP (3.5 (SD 0.1) \% NeuNAc and 1.5 (SD 0.1) \% Gal), glycosylated GMP (12.0 (SD 0.3)\% NeuNAc and 4.2 (SD 0.2) \% Gal) and a GMP-depleted whey protein concentrate, and to assess the effects of these fractions relative to glucose on CCK, subjective measures of satiety and food intake. In a randomised double-blind acute study, twenty overweight/obese males (56.9 (SD 7.2) years, $\left.97.4(\mathrm{SD} 8.1) \mathrm{kg}, 31.5(\mathrm{SD} 3 \cdot 0) \mathrm{kg} / \mathrm{m}^{2}\right)$ were recruited to consume four $50 \mathrm{~g}$ preloads (two GMP preparations, GMP-depleted whey and glucose) containing $895 \mathrm{~kJ}$. Blood samples and subjective measures of satiety were collected before and at 15,30,60, 90, 120 and 180 min after the consumption of preload, and CCK levels were measured. A lunchtime meal of hot food was provided from which subjects ate ad libitum until satisfied. Energy and nutrient intakes from the food consumed were calculated. There was no significant difference in CCK levels, subjective measures of satiety or food intake between treatments at the given preload level. These results suggest that the protein fractions at the dose employed do not influence satiety, CCK levels or energy intake at a subsequent meal.

Glycomacropeptide: Cholecystokinin: Food intake: Appetite: Satiety

Glycomacropeptide (GMP) is a C-terminal fragment of К-casein (residues 106-169) released by the endopeptidase chymosin (rennin). During commercial cheese making, this peptide is released into whey at a concentration of approximately $600 \mathrm{mg} / \mathrm{l}^{(1,2)}$. Oral GMP stimulates cholecystokinin (CCK), a candidate satiety hormone, which may make this protein a useful component of a weight loss diet because CCK slows gastric emptying, which may in turn promote satiety $^{(3-5)}$. GMP has also been detected in the blood of volunteers after milk or yogurt ingestion, suggesting that GMP can be formed in the gut and can be absorbed intact into intestinal cells ${ }^{(6)}$. We have shown previously that GMP was associated with reduced fat mass in Wistar rats fed ad libitum for 7 weeks with diets differing in protein-type amount ${ }^{(7)}$. In addition, it has been found that GMP $(33 \mathrm{~kJ})$ had no effect on satiety or on food intake $75 \mathrm{~min}$ after consumption, but it did reduce daily food intake ${ }^{(8)}$. However, Gustafson et al. ${ }^{(9)}$ reported no effect of GMP on subjective satiety or food intake at a test meal after the consumption of 0.4 and $2.0 \mathrm{~g}$ GMP in a $33 \mathrm{~kJ}$ preload; however, CCK was not measured, and various study design procedures, such as delivery with a low energy load, may have influenced the negative findings.
GMP naturally exists as a mixture of different glycoforms due to the carbohydrates sialic acid ( $N$-acetylneuraminic acid, galactose, galactosamine and glucosamine attached to the peptide by $O$-glycosidic linkages. There have been no reports showing the effect of these natural GMP glycoforms on CCK, subjective measures of satiety and food intake. The objective of the present study was therefore to examine the effect of different GMP glycoforms on CCK, subjective measures of satiety and food intake.

\begin{abstract}
Methods
GMP fractions from bovine cheese whey were manufactured using simulated moving bed chromatography on a Continuous Separations (Calgon Carbon Corporation, Pittsburgh, PA, USA) platform. This platform consisted of thirty columns of $4.6 \mathrm{~cm}$ diameter and $10 \mathrm{~cm}$ bed height packed with Pharmacia Q Sepharose Big Beads ion exchange resin (GE Healthcare, Uppsala, Sweden). The columns were equilibrated with reverse-osmosis water ( $\mathrm{pH} 4.0$ ) in the adsorption wash zone, followed by counter-current loading of the whey $(\mathrm{pH} \mathrm{4.0;}$ Bega Cheese Co., Bega, NSW, Australia). The columns were then rinsed with reverse-osmosis water at a neutral $\mathrm{pH}$,
\end{abstract}

Abbreviations: CSIRO, Commonwealth Scientific and Industrial Research Organisation; CCK, cholecystokinin; GMP, glycomacropeptide.

* Corresponding author: Dr Jennifer B. Keogh, fax +61 883038899, email jennifer.keogh@csiro.au 
and the glycosylated and minimally glycosylated GMP fractions were desorbed from the resin with $0.3 \mathrm{M}-\mathrm{NaCl}$ at pH 7.7 and was ultrafiltered using a spiral wound membrane (10 000 Da; Koch Membrane Systems, Inc., Wilmington, MA, USA). The flow through whey was ultrafiltered as described above to produce GMP-depleted whey protein concentrate. All samples were spray dried, and the $N$-acetylneuraminic acid, galactosamine and galactose contents of the glycosylated and minimally glycosylated GMP fractions were determined following a method that was similar to that reported previously for glycoprotein carbohydrates ${ }^{(10,11)}$.

The minimally glycosylated GMP contained $3 \cdot 5$ (SD $0 \cdot 1) \%$ $\mathrm{N}$-acetylneuraminic acid and 1.5 (SD 0.1$) \%$ galactose, and the glycosylated GMP contained 12.0 (SD 0.3 ) \% $N$-acetylneuraminic acid and 4.2 (SD 0.2$) \%$ galactose.

\section{Subjects and methods}

Twenty-two overweight or obese male volunteers $(56.3$ (SD 8.0) years) were recruited from the Commonwealth Scientific and Industrial Research Organisation (CSIRO) volunteer database.

Volunteers in this database are members of the public who have volunteered for studies at CSIRO and have provided consent to be contacted regarding a variety of studies. The present study was conducted according to the guidelines laid down in the Declaration of Helsinki, and all procedures involving human subjects were approved by the CSIRO Human Nutrition Human Research Ethics Committee. Written informed consent was obtained from all subjects.

Inclusion criteria were male sex, age 20-65 years and BMI $>25 \mathrm{~kg} / \mathrm{m}^{2}$, with no recent history (past 3 months) of weight loss or changes to diet or physical activity routine and an unrestrained eater (i.e. restrained eater questionnaire score $>10)^{(12)}$. Exclusion criteria were type 1 or type 2 diabetes or active liver and kidney disease as noted from medical questionnaire, current gastrointestinal disease, past history of gastrointestinal surgery which may affect study outcomes, hypersensitivity to study foods (casein, whey or wheat), medications which affect gastrointestinal motility or hunger/appetite (e.g. metoclopramide, domperidone and cisapride, anticholinergic drugs (e.g. atropine) and erythromycin) or inability to comprehend study protocol. Twenty male volunteers completed the study $\left(56.9\right.$ (SD 7.2) years, $97.4($ SD $8 \cdot 1) \mathrm{kg}$, BMI $31.5($ SD $\left.3 \cdot 0) \mathrm{kg} / \mathrm{m}^{2}\right)$. The volunteers in the study had a sedentary lifestyle estimated by a prestudy questionnaire. Two participants withdrew for personal reasons unrelated to the study.

The study was a randomised double-blind design of four different preload compositions with a $3 \mathrm{~d}$ interval between study treatments. The preload compositions were controlled for colour, taste and texture, and this was achieved by adding a non-nutritive artificially sweetened chocolate syrup. The nutrient composition of the chocolate syrup (per $70 \mathrm{~g}$ ) was $95 \mathrm{~kJ}, 0.4 \mathrm{~g}$ protein, $9.7 \mathrm{~g}$ carbohydrate and $0.2 \mathrm{~g}$ fat. The palatability of the preloads was tested by CSIRO staff before the study. The preloads were served in an opaque container, and were consumed through a straw to limit any effect of appearance or smell on response and palatability. Preload compositions were prepared on the day before the study. The amounts of protein in each of the test products used in the preloads were $41.3 \mathrm{~g}$ for the minimally glycosylated GMP fraction, $42.3 \mathrm{~g}$ for the glycosylated GMP fraction and $44.4 \mathrm{~g}$ for GMP-depleted whey protein concentrate fraction, and total energy intake of the preload compositions was $895 \mathrm{~kJ}$. Volunteers were asked to consume the preload within $5 \mathrm{~min}$ of commencing to drink.

A controlled meal was provided to each participant for consumption on the evening before trial commencement. This provided $3020 \mathrm{~kJ}, 58 \mathrm{~g}$ protein, $25 \mathrm{~g}$ fat, $56 \mathrm{~g}$ carbohydrate and $21 \mathrm{~g}$ fibre. Approximately, $25-30 \%$ of the estimated energy requirements were provided by the evening meal. The study participants were asked to abstain from alcohol consumption and to avoid excessive exercise on the evening before visiting the clinic. Volunteers were also asked to record any food eaten on the evening before each clinic visit. A hot lunchtime meal was provided for each participant $3 \mathrm{~h}$ after the preload treatment, where they could eat ad libitum until satisfied. Volunteers were given a choice of three options for this lunchtime meal: pasta with bolognaise sauce, veal casserole with rice or chicken curry with rice. In order to control for energy density, volunteers consumed the same meal for all the four study treatments. The amount of food given to each participant, the amount of food consumed and the amount remaining after eating until satisfied were weighed to calculate energy and nutrient intakes. This protocol has been described previously ${ }^{(13)}$.

Subjects rated their appetite using validated ${ }^{(14)}$ visual analogue scale before the preload and after every blood sample collection. The visual analogue scale was adapted to a sliding scale, computerised format (Northeast Data Corp. Slider ActiveX Custom Control (1.0) Charlotte, NC, USA) ${ }^{(13)}$. The questions were related to hunger, satisfaction, fullness and prospective food intake. A $100-\mathrm{mm}$ horizontal red line was shown below each question, and opposite extremes of the feeling were described at either end of the line. Subjects moved the cursor along the line using the mouse to indicate how they felt at that moment.

A cannula was inserted into a forearm vein, and a fasting blood sample was collected for each participant. The preload was consumed at approximately 09.00 hours, and subsequent blood samples were collected at 15, 30, 60, 90, 120 and $180 \mathrm{~min}$ after the consumption of the preload for the measurement of CCK. The cannula was removed after the final blood sample collection. Biochemical analyses for the satiety hormone CCK were performed after study completion on all blood samples that had been taken for each participant. We have described this protocol previously ${ }^{(13)}$.

The blood was collected in EDTA ( $1 \mathrm{~g} / \mathrm{l})$ tubes containing aprotinin (5000 KIU (Kallikrein inhibitor units) per $8 \mathrm{ml}$ blood; Mayne Pharma, Melbourne, Australia) and DPP-IV inhibitor $(80 \mu \mathrm{l}$ per $8 \mathrm{ml}$ blood; Australian Laboratory Services) and stored on ice until processed. The plasma was isolated by centrifugation for $10 \mathrm{~min}$ at $2000 \mathrm{~g},\left(5^{\circ} \mathrm{C}\right.$; Allegra XR-12 Centrifuge) and stored at $-80^{\circ} \mathrm{C}$ until analysis.

\section{Statistical analysis}

Statistical analyses were performed using SPSS 14.0 for WINDOWS (SPSS, Inc., Chicago, IL, USA). Repeatedmeasures ANOVA was used to assess the effect of time and the effect of treatment on the outcome variables measured, energy intake, CCK and subjective assessment of satiety. 
Table 1. Energy and macronutrient intakes at a hot buffet lunch $3 \mathrm{~h}$ after the consumption of preloads containing glycomacropeptide (GMP)-depleted whey protein concentrate (WPC) fraction, glycosylated GMP fraction, minimally glycosylated GMP fraction and glucose*

(Mean values and standard deviations)

\begin{tabular}{|c|c|c|c|c|c|c|c|c|}
\hline & \multicolumn{2}{|c|}{$\begin{array}{l}\text { GMP-depleted } \\
\text { WPC fraction }\end{array}$} & \multicolumn{2}{|c|}{$\begin{array}{l}\text { Glycosylated GMP } \\
\text { fraction }\end{array}$} & \multicolumn{2}{|c|}{$\begin{array}{l}\text { Minimally glycosy- } \\
\text { lated GMP fraction }\end{array}$} & \multicolumn{2}{|c|}{ Glucose } \\
\hline & Mean & SD & Mean & SD & Mean & SD & Mean & SD \\
\hline Energy (kJ) & 3985 & 917 & 3785 & 1037 & 3797 & 1023 & 3870 & 999 \\
\hline Protein $(\mathrm{g})$ & 63.8 & $18 \cdot 3$ & 61.3 & $19 \cdot 6$ & $61 \cdot 0$ & $16 \cdot 6$ & 63.4 & 18.7 \\
\hline Fat $(g)$ & 21.5 & 6.9 & $20 \cdot 6$ & $7 \cdot 1$ & $20 \cdot 6$ & $6 \cdot 6$ & 21.5 & $6 \cdot 8$ \\
\hline Carbohydrate (g) & 119.8 & $26 \cdot 6$ & $112 \cdot 5$ & 31.4 & $113 \cdot 6$ & 35.7 & $113 \cdot 4$ & 30.5 \\
\hline
\end{tabular}

* Data were analysed using repeated-measures ANOVA.

Statistical significance was set at $P \leq 0.05$. All data are presented as mean values and standard deviations.

\section{Results}

\section{Food intake}

Energy intake at the hot lunchtime meal was not different between treatments $(P=0.72): 3985$ (SD 917) kJ GMPdepleted whey protein concentrate fraction, 3785 (SD 1037) kJ glycosylated GMP fraction, 3797 (SD 1023) kJ minimally glycosylated GMP fraction and 3870 (SD 999) kJ glucose. In addition, there were no differences between treatments for protein $(P=0.71)$, fat $(P=0.70)$ or carbohydrate $(P=0.59)$ intake at the hot lunchtime meal (Table 1).

\section{Cholecystokinin}

There were no significant differences in CCK concentrations between the preload treatments $(P=0.45$; Fig. 1$)$.

\section{Visual analogue scale}

There was a time-by-treatment effect $(P=0.043)$ for the visual analogue scale question 'How satisfied do you feel?'. There were no differences in the visual analogue scale questions 'How hungry do you feel?' $(P=1 \cdot 0)$, 'How full do you feel?' $(P=0.952)$, 'How much do you think you can eat?' $(P=0.531)$, 'Would you like to eat something sweet?' $(P=0.239)$, 'Would you like to eat something salty?' $(P=0 \cdot 4)$, 'Would you like to eat something savoury?' $(P=0.295)$ and 'Would you like to eat something fatty?' $(P=0.728)$.

\section{Discussion}

The main findings of the present study were that none of the naturally occurring GMP glycoforms had an effect on CCK concentrations, subjective measures of satiety, and energy or macronutrient intake when compared with glucose.

These findings are in contrast to previous studies in which a glucose-containing preload compared with preloads containing a similar amount of protein from whey or casein was consumed $^{(15,16)}$. In a study by Bowen et al. ${ }^{(15)}$, nineteen overweight men consumed liquid preloads containing $52 \mathrm{~g}$ protein from whey or casein and $56 \mathrm{~g}$ lactose or glucose. In contrast to the present study, energy intake was $10 \%$ higher after the consumption of glucose preload compared with lactose and protein preloads $(P<0 \cdot 05)$. Also in contrast to the present study, CCK was $71 \%$ higher $90 \mathrm{~min}$ after the consumption of protein preloads compared with glucose and lactose $(P<0.05)$. In a second study by Bowen et al. ${ }^{(16)}$, liquid preloads containing $50 \mathrm{~g}$ protein from whey, soya and gluten, or $63 \mathrm{~g}$ glucose and $1200 \mathrm{~kJ}$ were consumed. Once again in contrast to the present study, energy intake was $10 \%$ lower after the consumption of all protein preloads compared with glucose $(P<0.05)$, and CCK concentrations were elevated after the consumption of protein preloads. It is not clear why differences between the protein and glucose preloads were not observed in the present study as the participants were similar in age and BMI. One reason may be that the protein content of the preloads was $10 \mathrm{~g}$ less and the energy was $170 \mathrm{~J}$ less in the present study, and differences may have been observed if the lunchtime meal had been offered earlier. The inter-meal interval of $3 \mathrm{~h}$ may have been too long to detect subtle differences. Evidence to support this is provided by Bowen et al. ${ }^{(16)}$, in which twenty-eight obese men consumed preloads containing $50 \mathrm{~g}$ whey, fructose, glucose or $25 \mathrm{~g}$ whey $+25 \mathrm{~g}$ fructose and $1100 \mathrm{~kJ}$. While CCK concentrations were increased after the consumption of protein preload, energy intake was not different between preloads. The inter-meal interval was $4 \mathrm{~h}$ in the present study, suggesting that this may have been too long to detect small

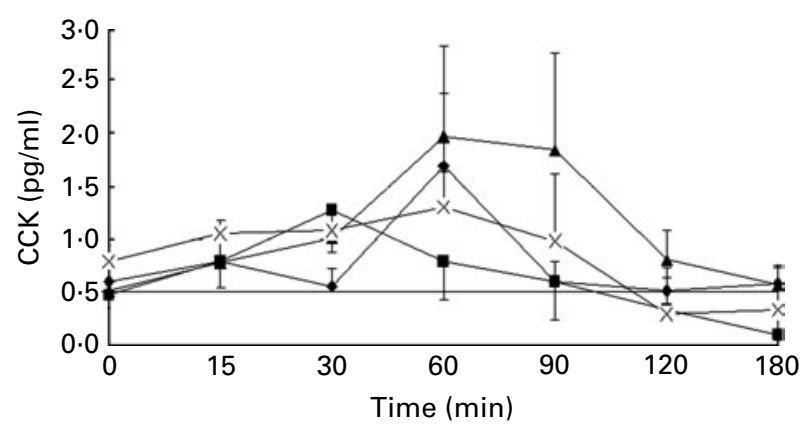

Fig. 1. The effect of four preloads containing either glycomacropeptide (GMP)-depleted whey protein concentrate (WPC) fraction, minimally glycosylated GMP fraction, glycosylated GMP fraction or glucose on plasma cholecystokinin (CCK) levels. Data are mean values with their standard errors. Data were analysed using repeated measures ANOVA. There was no time by treatment interaction $(P=0.45)$. $-\bullet-$, GMP-depleted WPC fraction; - - -, glycosylated GMP fraction; $-\boldsymbol{\Delta}-$, minimally glycosylated GMP fraction; $-\times-$, glucose. 
differences in energy intake. Veldhorst et al. found that energy intake at a lunchtime meal $3 \mathrm{~h}$ later was lower after a breakfast meal containing whey than after a breakfast containing whey without GMP, suggesting that GMP may have been responsible for the effect ${ }^{(17)}$. However, the energy content of the test breakfast used was 2520 (SD 70) kJ much greater than that in the present study, in which it was $895 \mathrm{~kJ}$. It may be that hunger from the lower energy load may have overwhelmed any subtle effect of either protein or GMP. The volunteers were also young and lean in the Veldhorst studies. Energy and nutrient intakes from the controlled meal the evening before in the present study may have been less than usual, further contributing to hunger. However, as we did not collect food records before the study, we do not know whether usual food intake was greater than that provided.

In a separate study, Veldhorst et al. ${ }^{(18)}$ found that whey was more satiating than either soya or casein only at the $10 \%$ of energy level and not at the $25 \%$ of energy level. But there were no differences in energy intake at either protein level. In a later study, Veldhorst et al. ${ }^{(19)}$ found that food intake at lunch was $20 \%$ lower $180 \mathrm{~min}$ after a breakfast containing $\alpha$-lactalbumin, gelatin or gelatin plus tryptophan compared with breakfast containing casein, soya, whey and whey with GMP, which were not different from each other.

Similar to the present results, Lam et al. ${ }^{(20)}$ observed that energy and macronutrient intakes were not different following preloads given $30 \mathrm{~min}$ before lunch containing maltodextrin, whey protein isolate with no GMP, whey protein isolate with $21 \%$ naturally present GMP or whey protein isolate with $21 \%$ naturally present GMP plus $20 \mathrm{~g}$ added GMP. The energy content of the preloads, $1300 \mathrm{~kJ}$, was greater than that in the present study with similar total protein $(43-46 \mathrm{~g})$ in the whey-containing preloads. Burton-Freeman ${ }^{(8)}$ also found that while satiety scores were greater after the consumption of protein preloads, energy and macronutrient intakes at a test lunch, $1 \mathrm{~h}$ after the consumption of preload, were not different between treatments. Preloads contained $1000 \mathrm{~kJ}$ energy and whey protein isolate, whey protein without GMP, GMP isolate $(0.8 \mathrm{~g})$ or a high carbohydrate control ${ }^{(8)}$. Thus, the majority of studies have not shown that whey with GMP or isolated GMP is superior to whey without GMP or indeed any other protein source. The level of GMP fed in the present study was also higher than that fed in any other study, positive or negative. Inconsistent effects of different proteins and peptides have been shown in other studies. Diepvens et al. ${ }^{(21)}$ observed lower hunger, desire to eat and thirst after consumption of pea compared with milk protein or combined pea and whey proteins $^{(21)}$. Pea and whey protein separately led to greater satiety and fullness compared with milk protein or the combined pea and whey proteins in overweight subjects given $1024 \mathrm{~kJ}$ and $15 \mathrm{~g}$ protein. However, despite these differences in subjective measures, there was no effect on energy intake.

It has been postulated that that $\mathrm{CCK}$ responses may be abnormal in obesity. Zwirska-Korczala et al. ${ }^{(22)}$ observed that fasting $\mathrm{CCK}$ concentrations were lower in morbidly obese individuals compared with lean controls, and that the postprandial CCK response was reduced in morbidly obese individuals ${ }^{(22)}$. However, in a study from our group by Bowen et al. ${ }^{(16)}$, there was no difference between lean and obese subjects in fasting CCK concentrations. Additionally, there was no effect of body weight on postprandial
CCK. The effect of body weight status on postprandial CCK responses remains to be clarified.

\section{Conclusions}

These results suggest that these protein fractions in the dose used were not effective in reducing food intake at a subsequent meal, and that they did not affect postprandial CCK concentrations. The extent of GMP glycosylation had no influence on the results.

\section{Acknowledgements}

The present study was funded by the CSIRO Food Futures Research Flagship. The authors have no conflicts of interest in relation to the present work. P. M. C. designed the study and contributed to interpretation of the data and the manuscript. J. B. K. contributed to the study design, managed the clinical trial, analysed the data and drafted the manuscript. B. W. W., C. M. T., F. J. and K. D. contributed to the development of the analysis method, the technology to produce the protein fractions and the manuscript. The help of the clinical research unit staff and laboratory staff at CSIRO Human Nutrition is gratefully acknowledged in the conduct of the study. We also thank the volunteers for participating in the study.

\section{References}

1. Nakano T, Silva-Hernandez E, Ikawa N, et al. (2002) Purification of kappa-casein glycomacropeptide from sweet whey with undetectable level of phenylalanine. Biotechnol Prog 18, 409-412.

2. Silva-Hernandez E, Nakano T \& Ozimek L (2002) Isolation and analysis of kappa-casein glycomacropeptide from goat sweet whey. J Agric Food Chem 27, 2034-2038.

3. Mangel AW \& Koegel A (1984) Effects of peptides on gastric emptying. Am J Physiol 246, G342-G345.

4. Yvon M, Beucher S, Guilloteau P, et al. (1994) Effects of caseinomacropeptide (CMP) on digestion regulation. Reprod Nutr Dev 34, 527-537.

5. Degen L, Matzinger D, Drewe J \& Beglinger C (2001) The effect of cholecystokinin in controlling appetite and food intake in humans. Peptides 22, 1265-1269.

6. Chabance B, Marteau P, Rambaud JC, et al. (1998) Casein peptide release and passage to the blood in humans during digestion of milk or yogurt. Biochimie 80, 155-165.

7. Royle PJ, McIntosh GH \& Clifton PM (2008) Whey protein isolate and glycomacropeptide decrease weight gain and alter body composition in male Wistar rats. Br J Nutr 100, 88-93.

8. Burton-Freeman BM (2008) Glycomacropeptide (GMP) is not critical to whey-induced satiety, but may have a unique role in energy intake regulation through cholecystokinin (CCK) Physiol Behav 28, 379-387.

9. Gustafson DR, McMahon DJ, Morrey J, et al. (2001) Appetite is not influenced by a unique milk peptide: caseinomacropeptide (CMP). Appetite 36, 157-163.

10. Honda S, Yamamoto K, Suzuki S, et al. (1991) High-performance capillary zone electrophoresis of carbohydrates in the presence of alkaline earth metal ions. J Chromatogr 588, 327-333.

11. Suzuki S, Yamamoto M, Kuwahara Y, et al. (1998) Separation of 1-phenyl-3-methyl-5-pyrazolone derivatives of monosaccharides by capillary electrochromatography. Electrophoresis 19, 2682-2688. 
12. Stunkard AJ \& Messick S (1985) The three-factor eating questionnaire to measure dietary restraint, disinhibition and hunger. J Psychosom Res 29, 71-83.

13. Bowen J, Noakes M \& Clifton PM (2007) Appetite hormones and energy intake in obese men after consumption of fructose, glucose and whey protein beverages. Int $J$ Obes (Lond) 31, 1696-1703.

14. Flint A, Raben A, Blundell JE, et al. (2000) Reproducibility, power and validity of visual analogue scales in assessment of appetite sensations in single test meal studies. Int $J$ Obes Relat Metab Disord 24, 38-48.

15. Bowen J, Noakes M, Trenerry C, et al. (2006) Energy intake, ghrelin, and cholecystokinin after different carbohydrate and protein preloads in overweight men. $J$ Clin Endocrinol Metab 91, 1477-1483.

16. Bowen J, Noakes M \& Clifton PM (2006) Appetite regulatory hormone responses to various dietary proteins differ by body mass index status despite similar reductions in ad libitum energy intake. J Clin Endocrinol Metab 91, 913-919.

17. Veldhorst MA, Nieuwenhuizen AG, Hochstenbach-Waelen A, et al. (2009) Effects of complete whey-protein breakfasts versus whey without GMP-breakfasts on energy intake and satiety. Appetite 52, 388-395.

18. Veldhorst MA, Nieuwenhuizen AG, Hochstenbach-Waelen A, et al. (2009) Dose-dependent satiating effect of whey relative to casein or soy. Physiol Behav 96, 675-682.

19. Veldhorst MA, Nieuwenhuizen AG, Hochstenbach-Waelen A, et al. (2009) A breakfast with alpha-lactalbumin, gelatin, or gelatin + TRP lowers energy intake at lunch compared with a breakfast with casein, soy, whey, or whey-GMP. Clin Nutr 28, 147-155.

20. Lam SM, Moughan PJ, Awati A, et al. (2009) The influence of whey protein and glycomacropeptide on satiety in adult humans. Physiol Behav 96, 162-168.

21. Diepvens K, Häberer D \& Westerterp-Plantenga M (2008) Different proteins and biopeptides differently affect satiety and anorexigenic/orexigenic hormones in healthy humans. Int $J$ Obes (Lond) 32, 510-518.

22. Zwirska-Korczala K, Konturek SJ, Sodowski M, et al. (2007) Basal and postprandial plasma levels of PYY, ghrelin, cholecystokinin, gastrin and insulin in women with moderate and morbid obesity and metabolic syndrome. J Physiol Pharmacol 58, Suppl. 1, 13-35. 